\title{
Assessment of waterborne coatings formulated with sol-gel/Ag related to fungal growth resistance
}

\author{
Romina Arreche ${ }^{\mathrm{a}, *}$, Natalia Bellotti ${ }^{\mathrm{b}}$, Cecilia Deyá ${ }^{\mathrm{b}}$, Patricia Vázquez ${ }^{\mathrm{a}}$ \\ ${ }^{\text {a } C I N D E C A-C e n t r o ~ d e ~ I n v e s t i g a c i o ́ n ~ y ~ D e s a r r o l l o ~ e n ~ C i e n c i a s ~ A p l i c a d a s, ~ ' D r . ~ J o r g e ~ J . ~ R o n c o ̈ ~(C C T-C O N I C E T) ~ U N L P, ~} 47$ N²57, La Plata, 1900 Buenos Aires, Argentina \\ b CIDEPINT-Centro de Investigación y Desarrollo en Tecnología de Pinturas (CIC-CONICET), Calle 52 e/121 y 122, La Plata, 1900 Buenos Aires, Argentina
}

\section{A R T I C L E I N F O}

\section{Keywords:}

Silica

Silver

Hygienic coatings

Bio-resistance

\begin{abstract}
A B S T R A C T
Fungal growth in damp surfaces of water-damaged buildings is an increasing problem around the world, which has adverse effects on both people's health and buildings. By bio-deterioration, fungi can growth in indoor environments and generate materials losses in addition to health problems. Therefore, antifungal coatings must be developed to avoid these problems. Silica is used as supporting additive in coatings, such as the waterborne paints and, on the other hand, the addition of $\mathrm{Ag}$ nanoparticles into different materials is being widely studied for its effective antimicrobial properties.

The aim of this work was to evaluate the bio-resistance to fungal growth on waterborne coatings containing siliceous additives, by accelerated four-week agar plate assay. The additives were synthesized by the sol-gel method and characterized by potentiometric titration and transmission electron microscopy (TEM). In addition, the paints were observed by scanning electron microscopy (SEM) at the end of the test. To carry out the bioresistance assay, Chaetomium globosum and Alternaria alternata fungi were used. After 4 weeks of assay, paints prepared with the silver-additives were the most efficient inhibiting the growth of both fungi. These paints, after their exposure for 6 months, in an internal environment with sunlight incidence, kept the antifungal activity against Chaetomium globosum and showed a higher activity against Alternaria alternata.
\end{abstract}

\section{Introduction}

The hygienic coatings are systems designed to avoid the microbial colonization and biofilm formation [1-3]. The development of these products has increased in the last few years and different companies around the world offer their products, focusing principally on hospitals and food industry [4-6]. Hygienic coatings can be formulated to generate easy-to-clean surfaces and to incorporate new bioactive compounds $[7,8]$. In general, the intention is to develop selective and integral methods that minimize biological risks, contributing to human health care [1]. There is no doubt that the colonization of microorganisms on buildings' walls generates esthetic problems and can lead to degradation of the coatings and loss of adhesion. Fungi are heterotrophic microorganisms that commonly colonize surfaces, especially in indoor buildings, using diverse materials as carbon source by their metabolism [9]. This fact produces not only esthetic problems, but also human health problems due to the production of allergens, irritants and mycotoxins in indoor environments [10,11]. Fungi of Alternaria genera are able to produce an important variety of compounds, among which mycotoxins are toxic to mammals and birds [12], whereas Chaetomium genera produce cellulolytic compounds that originate the degradation, especially of the waterborne paints, that contains cellulose thickeners [13].

Functionally, the antimicrobial coatings need to be effective against the growth of microorganism, whereas chemically, is very important the use of green̈ and no toxic compounds in their elaboration. Normal fungicides used in this type of control are often not appropriate in indoors applications, therefore, new alternatives, environmentally friendly and less toxic to human during preparation of the coatings are being investigated. Alternative bioactive compounds such as salicylate, benzoate and sorbate derivatives are investigated, based on alimentary industry preservatives [14] and, also silver, copper and zinc oxide nanoparticles result efficient against the different species evaluated [15-17]. In a previous work [18], the directly addition of metallic nanoparticles in an acrylic waterborne paint was evaluated. The four-week bio-resistance assay (ASTM D5590) showed that the best results were obtained with the paint containing silver and with smaller size $(10 \mathrm{~nm})$ at a concentration of $5.8 \mathrm{mg} / 100 \mathrm{~g}$ of paint. Assessment of the fungal growth degree on paints resulted in 1 and 2 for Chaetomium globosum and Alternaria alternata, which means trace of growth

\footnotetext{
* Corresponding author.

E-mail address: arrecheromina@gmail.com (R. Arreche).
} 
( $<10 \%)$ and light growth (10-30\%), respectively. The natural aging of these paints showed a decrease in efficiency of antifungal activity with both fungal species (unpublished results). This could be due silver nanoparticles are chemically very reactive and would be oxidized in contact with $\mathrm{TiO}_{2}$, a typical component of this type of paints [19]. In order to avoid this reduction in paint efficiency, the present work proposed to assess a variation to improve the addition of the active nanoparticles into paint formulations by supported these in a sol-gel matrix with the aim of extending their useful life. On the other hand, the use of nanoparticles to obtain efficient antimicrobial surfaces is complicated, taking into account, environmental concern, aggregation and uncontrollable release problems [20]. Therefore, the application of the sol-gel technique to associate the functional particles is a promising approach to the development of hygienic coatings formulations, due to that this would prolong the residence of the particles in their more active form as part of the protective system [21-23]. Despite the mechanism of antimicrobial effect of silver is still not fully understood there has been a growing interest in the broad antimicrobial properties of silver $(\mathrm{Ag})$ and it has been used in several technological areas [21-23].

The main purpose of the present work was to evaluate the fungal growth resistance of waterborne coatings obtained with siliceous solids as additives, by a procedure similar to the standard method ASTM D5590 [24]. The siliceous additives, synthesized by the sol-gel method, were characterized by potentiometric titration with $n$-butylamine, transmission electron microscopy (TEM) and their antifungal activity was assessed by the dilution method using two filamentous fungi, Chaetomium globosum and Alternaria alternata. Four paints were formulated and the bio-resistance assay was carried out. In addition, a set of coatings were aged in indoor environment conditions under natural sunlight after passing through a window glass for 6 months. Bright and color change of the coatings with and without the experimental antifungal additives were evaluated.

Observations by scanning electron microscopy (SEM) were made in order to observe the fungal growth on inoculated film paints after the bio-resistance test was concluded.

\section{Materials and methods}

\subsection{Synthesis of the siliceous additives}

The siliceous solids were prepared by the sol-gel method under a $\mathrm{N}_{2}$ atmosphere, using tetraethyl orthosilicate $\left(\mathrm{Si}\left(\mathrm{OCH}_{3}\right)_{4}-99.99 \%\right)$ (TEOS) as precursor, and acetic acid (AcH - 99.99\%) or molybdophosphoric acid $\left.\left(\mathrm{H}_{3}\left[\mathrm{P}\left(\mathrm{Mo}_{3} \mathrm{O}_{10}\right)_{4}\right)\right] \mathrm{xH}_{2} \mathrm{O}\right)$ (HPA) as catalyst of the sol-gel reaction, in order to obtain different structures of siliceous gels; whereas absolute ethanol $\left(\mathrm{CH}_{2} \mathrm{CH}_{3} \mathrm{OH}-99.9 \%\right)$ and distilled water (DW) were employed as solvents, and silver acetate $\left(\mathrm{CH}_{3} \mathrm{COOAg}-\right.$ 99.99\%) was added as antimicrobial agent. Four samples were obtained, two pure silicas, prepared with acetic acid (ST sample) and molybdophosphoric acid (ST-H sample) as catalyst respectively, a sample with HPA as catalyst and with the addition of silver acetate (ST-HAg sample), and finally, an impregnated sample (HAg/ST) by incipient wetting with HPA-Ag solution. For the synthesis, the catalyst was mixed with half amount of ethanol, then TEOS was added to the mixture and finally, silver acetate was incorporated with the rest of ethanol and the water. The homogeneous solution obtained was vigorously stirred for $2 \mathrm{~h}$ and, kept for 7 days at room temperature, for gelation and drying. In the samples prepared with acetic acid, the molar ratios of the reagents were 1:1.16:5:3.7 for precursor/catalyst/ solvent/water respectively, whereas in the samples prepared with HPA, the addition of the catalyst was done in order to reach a final concentration into the silica of $11 \mathrm{wt} . \%$ of HPA [25,26], and the molar ratios of the reagents were 1:0.005:5:3.7. In ST-HAg sample, silver acetate was added in the proper amount to occupy the half of the acid sites of HPA $\left(\mathrm{H}_{1.5} \mathrm{Ag}_{1.5}\right)$ and, in ST sample an ethanol solution of HPA-
Table 1

Nomenclature and compositions of synthesized solids (in molar ratio).

\begin{tabular}{lllllll}
\hline Sample & TEOS & AcH & HPA & $\mathrm{C}_{2} \mathrm{H}_{5} \mathrm{OH}$ & $\mathrm{H}_{2} \mathrm{O}$ & AgAc \\
\hline ST & 1 & 1.16 & - & 5 & 3.7 & 0 \\
ST-H & 1 & - & 0.005 & 5 & 3.7 & 0 \\
ST-HAg & 1 & - & 0.005 & 5 & 3.7 & 0.008 \\
HAg/ST & 1 & 1.16 & 0.005 & 5 & 3.7 & 0.008 \\
\hline
\end{tabular}

Ag, 11 wt.\% of HPA- 0.3 wt.\% of silver acetate, was added to obtain the impregnated solid ( $\mathrm{HAg} / \mathrm{ST}$ sample), then was stirred for $15 \mathrm{~min}$ and dried at room temperature. The nomenclature and composition of the synthesized solids are given in Table 1.

\subsection{Additives characterization}

\subsubsection{Potentiometric titration with n-butylamine}

The evaluation of the acidic properties of solids was achieved by potentiometric titration with $n$-butylamine, carried out in a Metrohm 794 Basic Titrino titrator, with a double-junction electrode. An nbutylamine solution in acetonitrile $(0.025 \mathrm{~N})$, at a $0.025 \mathrm{~mL} / \mathrm{min}$ rate, was added to $0.025 \mathrm{~g}$ of sample, previously suspended in acetonitrile $(45 \mathrm{~mL})$ and stirred for $3 \mathrm{~h}$.

\subsubsection{Transmission electron microscopy (TEM)}

The synthesized additives were characterized by transmission electron microscopy (TEM) to observe the shape and the size of the particles. The micrographs were obtained with a JEOL microscope; model $100 \mathrm{CX}$, at an accelerating voltage of $100 \mathrm{kV}$. Each sample was suspended in ethanol and placed into an ultrasonic bath for $15 \mathrm{~min}$ to improve the dispersion. Then, some drops were placed on the microscope grid with a Formvar film and dried for $30 \mathrm{~min}$ at room temperature.

\subsection{Antifungal activity}

The assessment of their antifungal activity was done by the dilution method against Alternaria alternata and Chaetomium globosum [27,28]. These molds were isolated from bio-deteriorated coatings in a previous work [18]. This method allows us to determine the inhibition percentage of the fungal growth, according to the radial growth of fungi, by measuring colony diameters on agar plates and assessing the effect of the medium composition where they are growing. In order to set the concentration of experimental additives to test in culture media, the amount of silver in each solid was taking into account [29]. At the same time, plates were prepared, as controls, adding the same amount of the solids to be test, without $\mathrm{Ag}$ in their composition.

Petri dishes were prepared with $15 \mathrm{~mL}$ of the culture media (CMagar): $2.5 \mathrm{~g}$ glucose, $1.25 \mathrm{~g}$ peptone, $0.25 \mathrm{~g} \mathrm{KH}_{2} \mathrm{PO}_{4}, 0.125 \mathrm{~g} \mathrm{MgSO}_{4}$ $7 \mathrm{H}_{2} \mathrm{O}, 4.0 \mathrm{~g}$ of agar and up to $250 \mathrm{~mL}$ of distilled water (DW). Then, $0.001,0.01$ or $0.05 \%$ (weight/volume) of $\mathrm{Ag}$ was added to the medium, in relation to the content of $\mathrm{Ag}$ of the tested solids and, on the other hand, the equivalent solids without $\mathrm{Ag}$ in their composition were added in the same amount to CM-agar plates. Finally, controls without any additive were prepared. Duplicates were set up for each concentration, including the controls. The petri dishes were inoculated in the center with $20 \mu \mathrm{L}$ of spores suspension $\left(10^{5}\right.$ spores $\left./ \mathrm{mL}\right)$ of Alternaria alternata or Chaetomium globosum, and then incubated at $26 \pm 2{ }^{\circ} \mathrm{C}$ for 9 and 10 days with the respectively fungus. With the obtained results, the inhibition percentage (I\%) was calculated according to Eq. (1), where C and $\mathrm{E}$ correspond to the average diameter of each fungus in the control plate and on the plate with the tested solids, respectively. Three measurements of the fungal growth diameter were made in each plate and standard deviation was determined.

Inhibition $(\%)=[(\mathrm{C}-\mathrm{E}) / \mathrm{C}] \times 100[30]$ 
Table 2

Composition of the paints used in this study (in wt.\%).

\begin{tabular}{lllll}
\hline Function & P Control & P ST & P ST-HAg & P HAg/ST \\
\hline Water & 26.80 & 26.80 & 26.80 & 26.80 \\
Defoamer & 0.27 & 0.27 & 0.27 & 0.27 \\
Thickener & 0.55 & 0.55 & 0.55 & 0.55 \\
Dispersant & 0.47 & 0.47 & 0.47 & 0.47 \\
Humectant & 0.05 & 0.05 & 0.05 & 0.05 \\
Resin & 7.20 & 7.20 & 7.20 & 7.20 \\
Titanium dioxide & 19.80 & 19.80 & 19.80 & 19.80 \\
Calcium carbonate & 42.10 & 37.10 & 37.10 & 37.10 \\
Preservative & 0.25 & 0.25 & 0.25 & 0.25 \\
Coalescent & 1.88 & 1.88 & 1.88 & 1.88 \\
Deodorant & 0.63 & 0.63 & 0.63 & 0.63 \\
ST additive & - & 5.00 & - & - \\
ST-HAg additive (1\%wt. Ag) & - & - & 5.00 & - \\
HAg/ST additive (1\%wt. Ag) & - & - & - & 5.00 \\
\hline
\end{tabular}

\subsection{Coatings bio-resistance assay}

Four water-borne paints were prepared for their evaluation and comparison, employing an acrylic resin; one of the paints was prepared as control, without any antimicrobial additive, and three paints were prepared with similar formulation, but adding the experimental antifungal additives at a concentration of $5 \mathrm{~g}$ for $100 \mathrm{~g}$ of total paint formulation. Table 2 shows the composition of the paints used in this study (in wt.\%). The preparation of the paints was done with a highspeed disperser and then, glass slides were painted (with two layers of paint), and dried for 15 days under dark condition before testing. The pieces were cut in squares of $2.5 \mathrm{~cm} \times 2.5 \mathrm{~cm}$ and irradiated under germicide UV Philips light ( $20 \mathrm{~W}$ ), for $40 \mathrm{~min}$ each side to decontaminate the surface before test and to avoid the growth of other microorganisms. The painted glasses were placed in mineral media: $5 \mathrm{~g} \mathrm{NaCl}$, $1 \mathrm{~g} \mathrm{HK}_{2} \mathrm{PO}_{4}, 1 \mathrm{~g}\left(\mathrm{NH}_{4}\right) \mathrm{H}_{2} \mathrm{PO}_{4}, 1 \mathrm{~g}\left(\mathrm{NH}_{4}\right)_{2} \mathrm{SO}_{4}, 0.2 \mathrm{~g} \mathrm{MgSO}_{4}, 3 \mathrm{~g} \mathrm{KNO}$, $15 \mathrm{~g}$ of agar and up to $1000 \mathrm{~mL}$ of distilled water. Then, the glasses were inoculated with $50 \mu \mathrm{L}$ of a spore suspension $\left(10^{5}\right.$ spores $\left./ \mathrm{mL}\right)$ of each fungal species, and finally, this suspension was distributed homogeneously all over the painted surface. After 1 month, the glasses incubated at $28{ }^{\circ} \mathrm{C}$ were evaluated according to ASTM D5590 standard specification [24] that states a degree of fungal growth according to: none, trace of growth $(<10 \%)$, light growth (10-30\%), moderate growth (30-60\%), heavy growth $(60-100 \%)$ rating as $0,1,2,3$ and 4 , respectively.

Two sets of glasses were painted; one set was tested after 15 days of curing while the other was tested after 6 months of sunlight exposure through a window (natural aging), by simulating natural conditions in an indoor environment.

\subsection{Observation of the paints by scanning electron microscopy (SEM)}

The painted glasses were observed by SEM before and after the bioresistance assay employing Philips 505 equipment, using a voltage of $15 \mathrm{kV}$, and supporting the samples on graphite and covering with gold. The images were obtained with an ADAII acquisition device (Soft Imaging System).

\subsection{Color and gloss measurements}

CIElab color parameters were evaluated on dried paints during their sunlight exposure through a window. The CIElab diagram represents the area where all the real colors are placed, according to the CIElab transformation. In the center, the luminosity of the color is placed and the vertical axis, $L$, varies from 0 to 100 (white). The other two orthogonal axis form the chromaticity plane, represented by $a$ and $b$. This is based on the opponents color criteria, the variation magenta- blue green $(a)$ and yellow-blue $(b)$.

$\delta \mathrm{E}$, the change of color, was calculated as [31]:

$\delta E=\left[\left(L-L_{s}\right)^{2}+\left(a-a_{s}\right)^{2}+\left(b-b_{s}\right)^{2}\right]^{1 / 2}$

being $L, a$ and $b$ the CIElab parameters for the control paint and $L s$, as and $b s$, the corresponding ones for the paints with the studied solids. Gloss parameter was also measured, employing a ByK Gardner glossmeter.

\section{Results and discussion}

\subsection{Additives characterization}

The potentiometric titration is a method to estimate the acidic properties of samples and it is based on the difference in the electrode potential. In order to analyze the results, it is suggested that the initial electrode potential $\left(\mathrm{E}_{\mathrm{i}}\right)$ indicates the maximum acid strength of the surface sites and, the value can be classified according to the following ranges: very strong sites, $E_{i}>100 \mathrm{mV}$; strong sites, $0<\mathrm{E}_{\mathrm{i}}>100 \mathrm{mV}$; weak sites, $-100 \mathrm{mV}<\mathrm{E}_{\mathrm{i}}>0$ and very weak sites, $E_{i}<-100 \mathrm{mV}[32,33]$. When acetic acid or molybdophosphoric acid were used in the synthesis, a variation of $E_{i}$ was observed. ST and ST-H samples presented $E_{i}$ values of $135 \mathrm{mV}$ and $463 \mathrm{mV}$ respectively, showing an increase of the acidity when HPA is used as catalyst, because of an extremely high initial acidic strength $(800 \mathrm{mV})$ of the commercial heteropolyacid (HPA) [26]. When silver was added into the synthesis (ST-HAg sample) the $E_{i}$ value decreased to $99 \mathrm{mV}$, showing a substitution of HPA protons by silver ions. No significant differences were found with the impregnated sample, which showed a value of $E_{i}$ of $70.9 \mathrm{mV}$.

Fig. 1 shows the characterization of the additives by TEM. The micrographs of ST and ST-H samples (Fig. 1a and b) shows silica particles with sizes between $50 \mathrm{~nm}$ and $0.3 \mu \mathrm{m}$, formed by clusters of rounded nanoparticles of 10 and $20 \mathrm{~nm}$. When HPA was used as catalyst, the micrograph shows the presence of agglomerates of silica particles, probably due to the presence of HPA inside the silica pores and, when silver was added to the synthesis in ST-HAg sample (Fig. 1c), $\mathrm{Ag}$ nanoparticles with heterogeneous size were observed into the silica matrix, resulting mostly in the order of $10 \mathrm{~nm}$. Finally, the TEM micrograph of the impregnated $\mathrm{HAg} / \mathrm{ST}$ sample (Fig. 1d), shows a uniform distribution of the $\mathrm{Ag}$ particles and sizes under the $10 \mathrm{~nm}$.

\subsection{Antifungal activity}

The antifungal activity of the additives was assessed using the dilution method, by measuring the diameters of the fungal growth on CM-agar, against time. Fig. 2 shows the results of the assays employing a concentration of $0.01 \%(\mathrm{w} / \mathrm{v})$ against $A$. alternata y $C$. globosum, with the corresponding control plates and, Fig. 3 shows the inhibition percentages, calculated employing Eq. (1), for all the concentrations used.

According to the results, we found that the inhibition of the fungal growth increased as the amount of additive in the culture medium was higher and, almost all samples showed a $100 \%$ of inhibition at the concentration of $0.05 \%(\mathrm{w} / \mathrm{v})$ with or without the presence of silver. Although silver was absent in samples ST and ST-H, their strong acidic sites might be responsible for their antifungal activity. By comparing ST-HAg and HAg/ST samples with ST and ST-H samples, an increase in the inhibition was observed due to the presence of the metallic ion, and the same tendency was observed for both fungi. The best results were obtained with the impregnated sample (HAg/ST), showing the higher inhibition with the intermediate concentration $(0.01 \% \mathrm{w} / \mathrm{v})$, against both fungal species. 


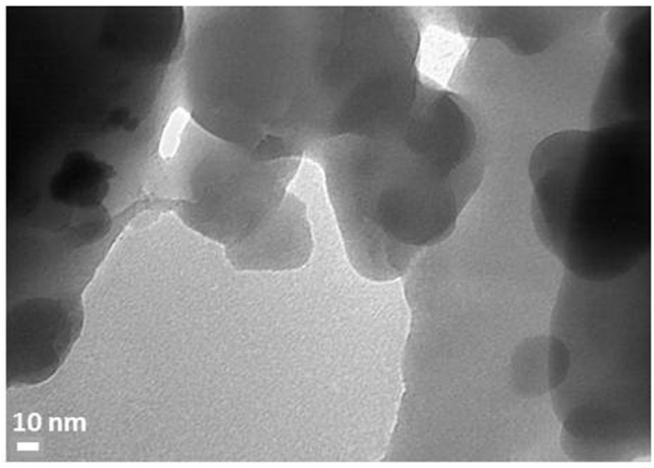

(a)

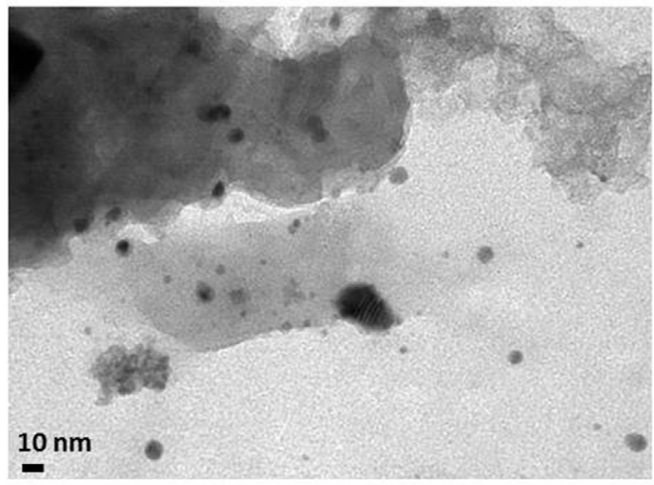

(c)

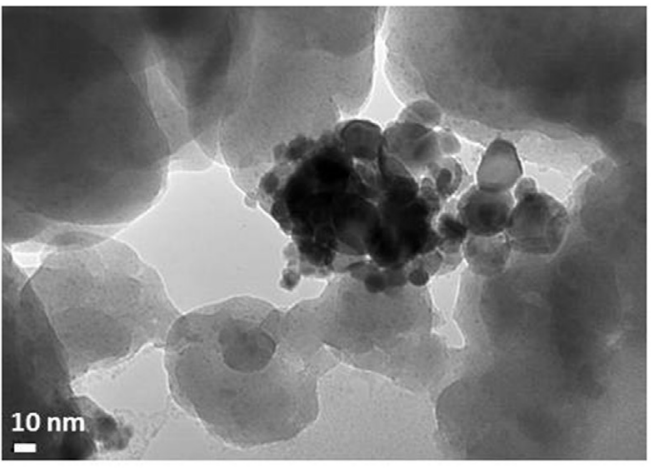

(b)

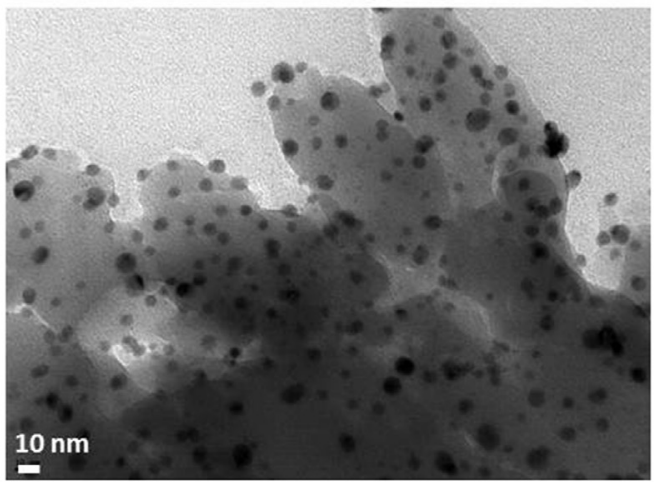

(d)

Fig. 1. TEM micrographs of the additives (a) ST, (b) ST-H, (c) ST-HAg and (d) HAg/ST (Bar: $10 \mathrm{~nm}$ ).

\subsection{Bio-resistance of the paints}

According to the previous results of acidity and antifungal activity of ST-H sample, we considered that this sample was not appropriate for be used as fillers in coatings. Therefore, after the assessment of the antifungal activity, the selected additives were incorporated into waterborne paints and the bio-resistance on paint films was evaluated employing the ASTM D5590 standard.

The results of the bio-resistance assay are shown in Figs. 4 and 5.
Among the formulated paints, the control paint (P control) and the one containing the ST-additive (P ST) showed significant differences compared with the paints containing Ag, showing a developed mycelium that covered more than $60 \%$ of the exposed surfaces and evidencing no major impediment against fungal growth. In paints with ST-HAg and HAg/ST additives (P ST-HAg and P HAg/ST, respectively), the fungal growth degree was less and the inhibition effect was higher. Moderate growth (30-60\%) was observed against $A$. alternata, whereas a trace of growth $(<10 \%)$ was observed against $C$. globosum, therefore,

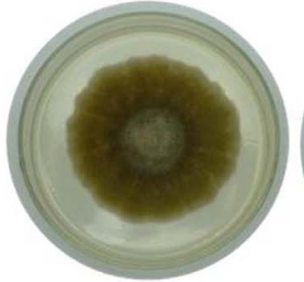

a) Control

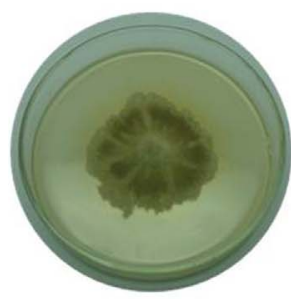

f) Control

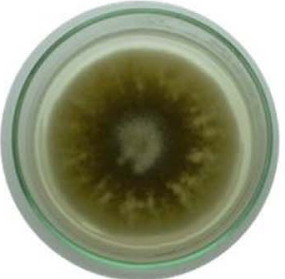

b) ST

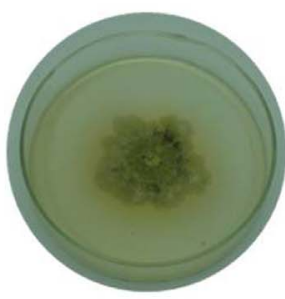

g) ST

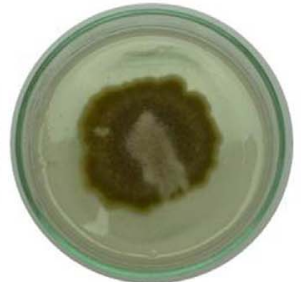

c) ST-H

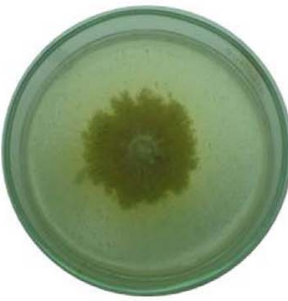

h) ST-H

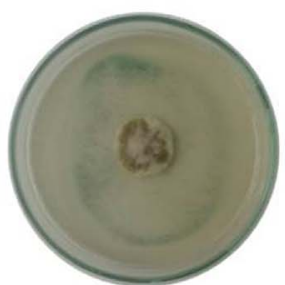

d) ST-HAg



i) ST-HAg

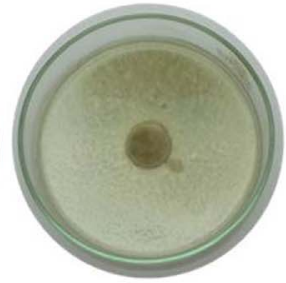

e) $\mathrm{HAg} / \mathrm{ST}$

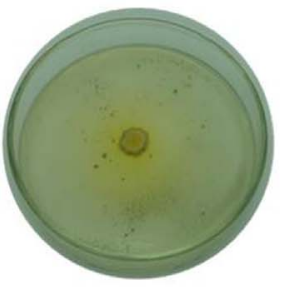

j) $\mathrm{HAg} / \mathrm{ST}$

Fig. 2. Alternaria alternata (a-e) and Chaetomium globosum (f-j) growth in CM-agar plates, after a week at $26 \pm 2{ }^{\circ} \mathrm{C}$ with and without $0.01 \%$ (w/v) of the additives. 


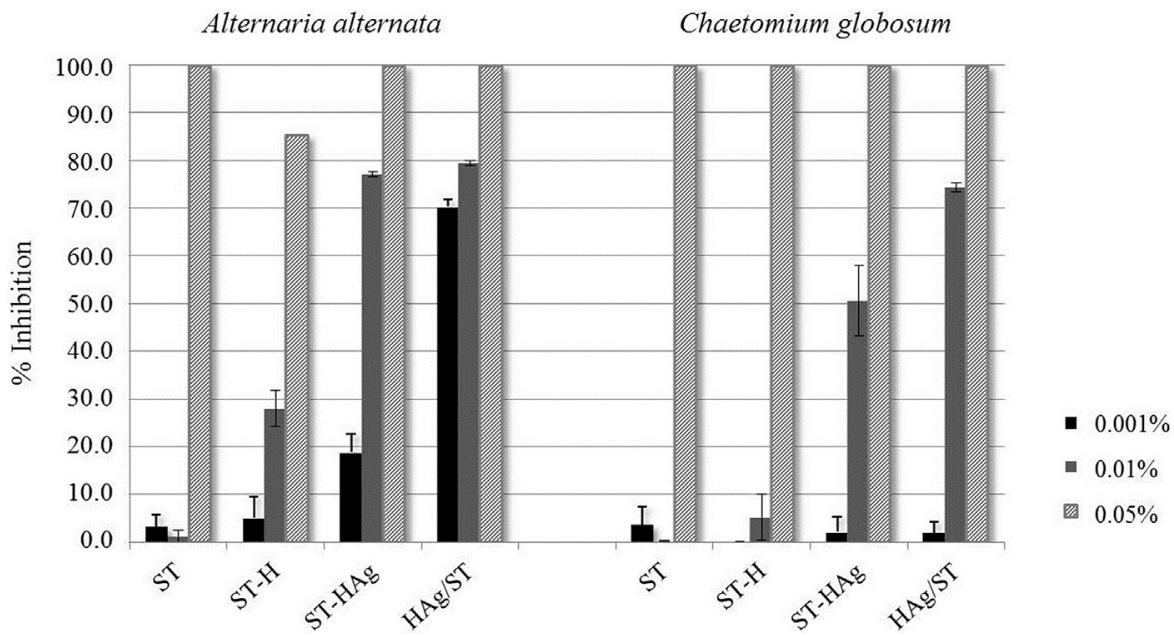

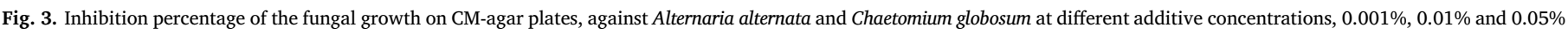
$(\mathrm{w} / \mathrm{v})$.

this fungus was more affected by the paints with the Ag-additives.

The set of glasses exposed to sunlight for 6 months, through a window in an indoor environment, showed that the inhibitive power of the paints containing Ag was kept along the time. Moreover, against $A$. alternata, the inhibition was increased, as the growth degree of this fungus was lower after 6 months of application of the paints, while against C. globosum, the inhibition degree of inhibition remains.

\subsection{SEM observation of the paints films}

When the paints obtained with the synthesized solids, incorporated as additives in the formulation, were compared with the control paint, apparently no differences of physical properties have been found. However, the SEM micrographs before the bio-resistance assay showed that the incorporation of the synthesized additives into the paints generated a rougher surface on the paint films.

Figs. 6 and 7 show the SEM micrographs obtained of the film surfaces after 4 weeks of assay, against A. alternata and C. globosum, respectively. The fungal development on control (Figs. $6 \mathrm{a}$ and $7 \mathrm{a}$ ) and ST paints (Figs. $6 \mathrm{~b}$ and $7 \mathrm{~b}$ ) was particularly evident, covering almost all the surface and showing an active growth of the mycelium with an important hyphae network. On the other hand, the paints with the Agadditives, not only those with the silver salt added from the beginning of the sol-gel reaction (Figs. $6 \mathrm{c}$ and $7 \mathrm{c}$ ), but also the impregnated samples (Figs. $6 \mathrm{~d}$ and $7 \mathrm{~d}$ ), showed that the spore germination and hyphae development was inhibited, exhibiting the fungal spores, previously seeded, without development. Therefore, the most efficient paints inhibiting the fungal growth, after 4 weeks of assay, were those with $\mathrm{Ag}$ in their composition.

Moreover, paints exposed to sunlight for 6 months, and after the bio-resistance assay, showed by SEM that, those without Ag in their composition (control paint and ST paint) presented a heavy growth against both fungi and, particularly against C. globosum, an active mycelium growth was observed, developing an important hyphae network that extends all over the surface, beside a great number of secondary spores (as a result of the fungal development). In the micrographs (not shown), the interaction between the hyphae and the paints was observed in detail, showing an invasive behavior with the mycelium breaking the integrity of the paint and it penetrate the paint film. In contrast, in the paints with $\mathrm{Ag}$ in their composition (STH-Ag and $\mathrm{HAg} / \mathrm{ST}$ paints) the spore germination and hyphae development were inhibited and no breakdown of the film was observed. The spores

\begin{tabular}{|c|c|c|c|c|}
\hline A. alternata & P Control & PST & P ST-HAg & P HAg/ST \\
\hline $\begin{array}{l}\text { No sunlight } \\
\text { exposure }\end{array}$ & & & & \\
\hline ASTM & 4 & 4 & $3-4$ & 3 \\
\hline $\begin{array}{l}\text { Sunlight } \\
\text { exposure } \\
\text { ( } 6 \text { months) }\end{array}$ & & 2 & & \\
\hline ASTM & 4 & 4 & 1-2 & 1-2 \\
\hline
\end{tabular}

Fig. 4. Paint bio-resistance assay against $A$. alternata and fungal growth degree from bio-resistance assay. 


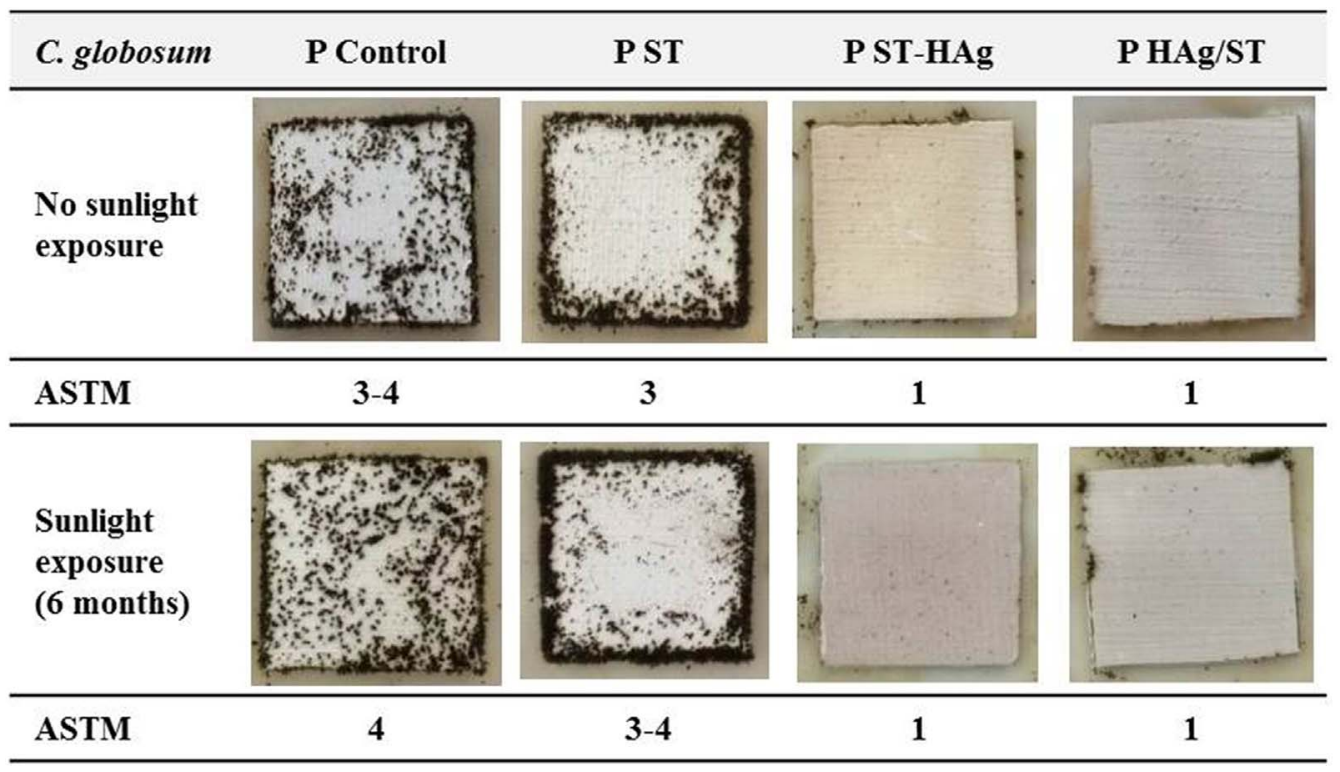

Fig. 5. Paint bio-resistance assay against $C$. globosum and fungal growth degree from bio-resistance assay.

localized on the surface of the paint film correspond to those deposited to carry out the assay and no fungal growth was developed.

\subsection{Color and gloss measurements}

During the exposure of the films to sunlight for 6 months, the paints

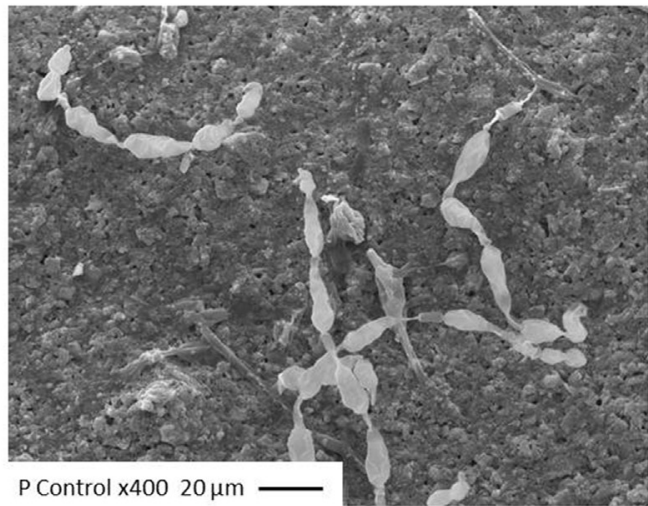

(a)

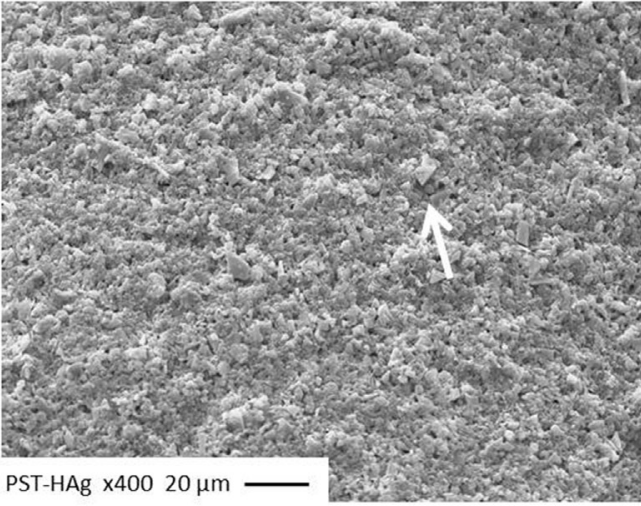

(c) suffered important changes in color but the gloss was almost constant and around 1.5-2.3 for all the formulated paints (Fig. 8). These values are common for ceiling paints (IRAM 1109). The color changes are important in those paints that have $\mathrm{Ag}$ in their composition, probable due to the reaction of Ag. The main color change is to the yellowing side of the color CIELab spectra.

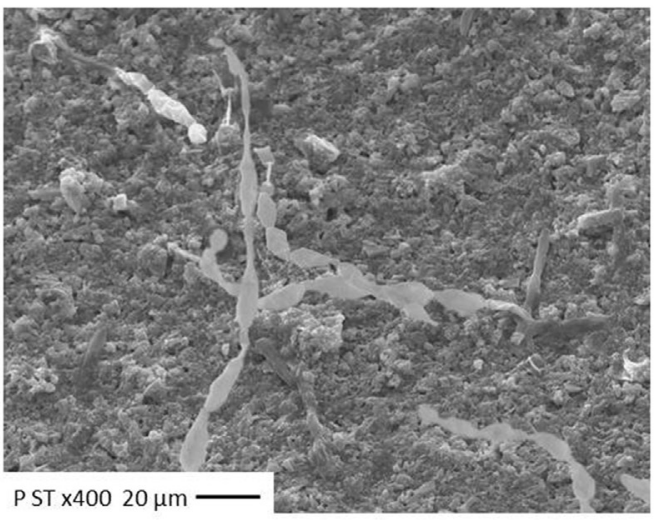

(b)

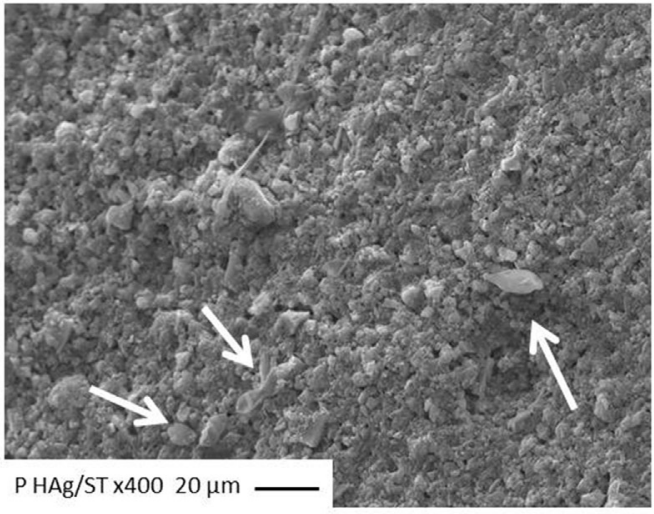

(d)

Fig. 6. SEM micrographs of the paints inoculated with A. alternata, (a) control, (b) ST, (c) ST-HAg and (d) HAg/ST (400x). Spores are pointing out with white arrows. 


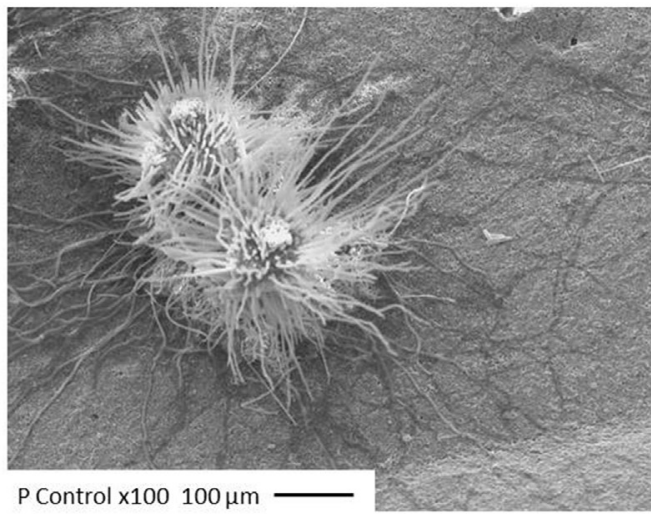

(a)

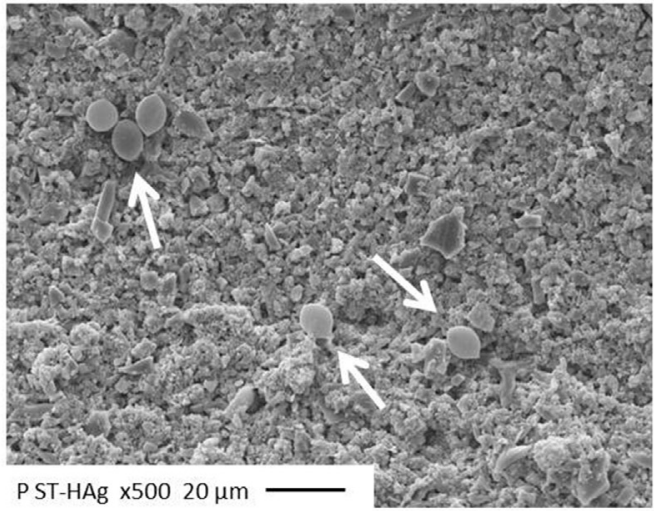

(c)

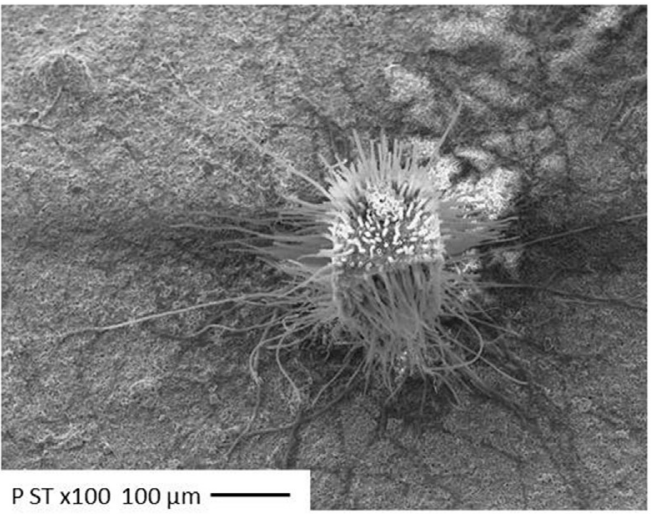

(b)

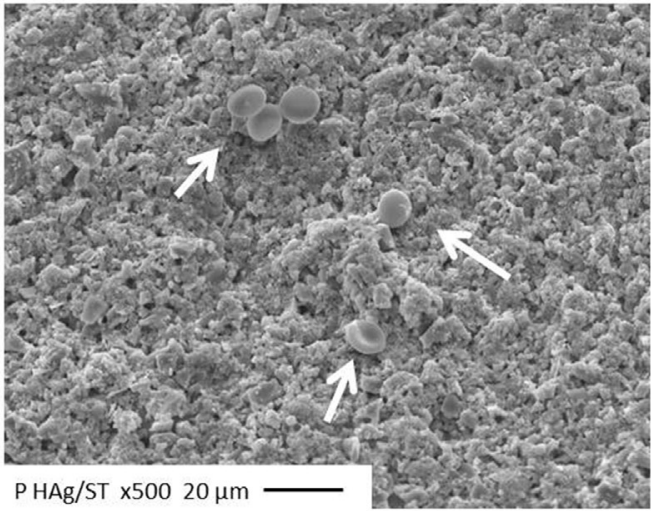

(d)

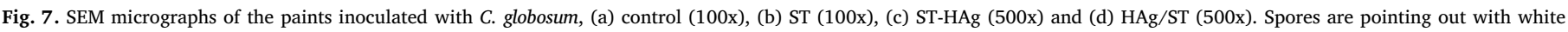
arrows.

\section{Conclusions}

According to the results, antimicrobials additives were obtained by the sol-gel method by inhibiting the growth of $C$. globosum and $A$. alternata in agar plate assays, being the most efficient those with $\mathrm{Ag}$ in their composition. The best results were obtained with the impregnated sample $(\mathrm{HAg} / \mathrm{ST})$ probably due to a uniform distribution of $\mathrm{Ag}$ nanoparticles and sizes under the $10 \mathrm{~nm}$.

When the synthesized additives were included into the paints, rougher surfaces were observed on the paint films. Ag-additives resulted active against the tested fungi, reducing the fungal growth in the coatings and being the inhibition against $C$. globosum more important. After 6 months of sunlight exposure, the antifungal activity of the paints with Ag-additives was kept and an increased was observed against $A$. alternata, as the growth degree of this fungus was lower after 6 months of application.

The inhibition efficiency of the synthesized additives might be related, firstly with the Ag-presence and, secondly with the silver availability to interact with fungi, in addition with the size of the nanoparticles. A smaller size of Ag-nanoparticles and a homogeneous distribution in the additives matrix improved the antimicrobial activity. These results corroborate those obtained in previously research [18].
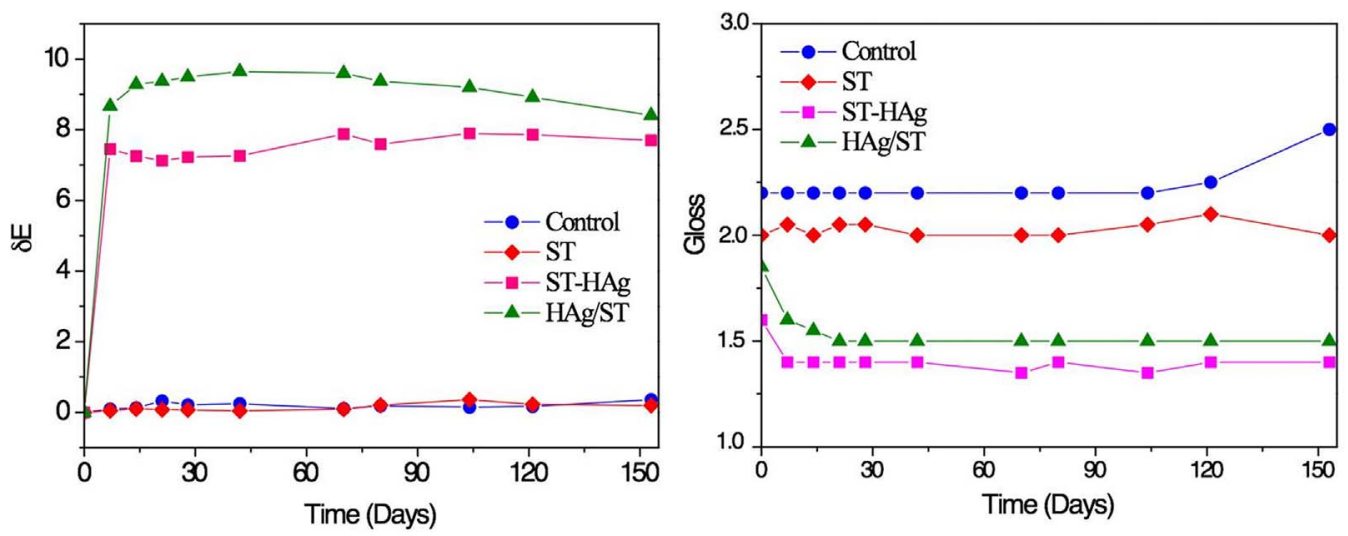

Fig. 8. Change of color $(\delta \mathrm{E})$ and gloss of the painted panels during the sunlight exposure behind a window. 


\section{Acknowledgments}

The authors thank Mariela Theiller for providing the SEM images and to CONICET (Consejo Nacional de Investigaciones Científicas y Técnicas), CICPBA (Comisión de Investigaciones Científicas de la provincia de Buenos Aires) and UNLP (Universidad Nacional de La Plata) for the support of this research work.

\section{References}

[1] K. Johns, Surf. Coat. Int. B: Coat. Trans. 86 (2003) 101-110, http://dx.doi.org/10. 1007/BF02699620.

[2] N. Stobie, B. Duffy, J. Colreavy, P. McHale, S.J. Hinder, D.E. McCormack, J. Colloid Interface Sci. 345 (2010) 286-292, http://dx.doi.org/10.1016/j.jcis.2010.02.009.

[3] G. Gozzelino, A.G. Dell'Aquila, D. Romero, J. Coat. Technol. Res. 7 (2010) 167-173, http://dx.doi.org/10.1007/s11998-009-9187-z.

[4] A.L. Casey, D. Adams, T.J. Karpanen, P.A. Lambert, B.D. Cookson, P. Nightingale, L. Miruszenko, R. Shillam, P. Christian, T.S.J. Elliott, J. Hosp. Infect. 74 (2010) 72-77, http://dx.doi.org/10.1016/j.jhin.2009.08.018.

[5] K. Page, M. Wilson, I.P. Parkin, J. Mater. Chem. 19 (2009) 3819-3831, http://dx. doi.org/10.1039/B818698G.

[6] L.J. Bastarrachea, A. Denis-Rohr, J.M. Goddard, Annu. Rev. Food Sci. Technol. 6 2015) 97-118, http://dx.doi.org/10.1146/annurev-food-022814-015453.

[7] C. Rabinovitch, P.S. Stewart, Appl. Environ. Microbiol. 72 (2006) 6364-6366, http://dx.doi.org/10.1128/AEM.00442-06.

[8] T. Matsunaga, T. Nakayama, H. Wake, M. Takahashi, M. Okochi, N. Nakamura, Biotechnol. Bioeng. 59 (2000) 374-378, http://dx.doi.org/10.1002/(SICI)10970290(19980805)59:3 < 374:AID-BIT14 > 3.0.CO;2-E.

[9] D.W. Li, C.S. Yang, Adv. Appl. Microbiol. 55 (2004) 31-112, http://dx.doi.org/10 1016/S0065-2164(04)55002-5.

[10] J.D. Cooley, W.C. Wong, C.A. Jumper, D.C. Straus, Adv. Appl. Microbiol. 55 (2004) 1-30, http://dx.doi.org/10.1016/S0065-2164(04)55001-3.

[11] E. Bloom, L.F. Grimsley, C. Pehrson, J. Lewis, L. Larsson, Indoor Air 19 (2009) 153-158, http://dx.doi.org/10.1111/j.1600-0668.2008.00574.x.

[12] D. Sullivan, G. Moran, D. Coleman, K. Kavanagh (Ed.), Fungi, Biology and Applications, John Wiley \& Sons, England, 2005, pp. 171-217.

[13] C.J. Alexopoulos, C.W. Mims, Introducción a la micología, 1st ed., Omega, Barcelona, 1985.

[14] N. Bellotti, L. Salvatore, C. Deyá, M.T. del Panno, B. del Amo, R. Romagnoli, Colloids Surf. B 104 (2013) 140-144, http://dx.doi.org/10.1016/j.colsurfb.2012. 11.037.
[15] J. Pasquet, Y. Chevalier, J. Pelletier, E. Couval, D. Bouvier, M.A. Bolzinger, Colloids Surf. A: Physicochem. Eng. Asp. 457 (2014) 263-274, http://dx.doi.org/10.1016/j. colsurfa.2014.05.057.

[16] J.P. Ruparelia, A.K. Chatterjee, S.P. Duttagupta, S. Mukherji, Acta Biomater. 4 (2008) 707-716, http://dx.doi.org/10.1016/j.actbio.2007.11.006.

[17] G. Ren, D. Hu, E.W.C. Cheng, M.A. Vargas-Reus, P. Reip, R.P. Allaker, Int. J. Antimicrob. Agents 33 (2009) 587-590, http://dx.doi.org/10.1016/j.ijantimicag. 2008.12.004.

[18] N. Bellotti, R. Romagnoli, C. Quintero, C. Domínguez-Wong, F. Ruiz, C. Deyá, Prog. Org. Coat. 86 (2015) 33-40, http://dx.doi.org/10.1016/j.porgcoat.2015.03.006.

[19] L. Pinho, M. Rojas, M.J. Mosquera, Appl. Catal. B: Environ. 178 (2015) 144-154, http://dx.doi.org/10.1016/j.apcatb.2014.10.002.

[20] L. Guo, W. Yuan, Z. Lu, C.M. Li, Colloids Surf. A: Physicochem. Eng. Asp. 439 (2013) 69-83, http://dx.doi.org/10.1016/j.colsurfa.2012.12.029.

[21] M. Bellantone, N.J. Coleman, L. Hench, J. Biomed. Mater. Res. 51 (2000) 484-490, http://dx.doi.org/10.1002/1097-4636(20000905)51:3<484:AID-JBM24 > 3.0 $\mathrm{CO} ; 2-4$.

[22] H.J. Jeon, S.C. Yi, S.G. Oh, Biomaterials 24 (2003) 4921-4928, http://dx.doi.org/ 10.1016/S0142-9612(03)00415-0

[23] S. Jaiswal, P. McHale, B. Duffy, Colloids Surf. B Biointerfaces 94 (2012) 170-176, http://dx.doi.org/10.1016/j.colsurfb.2012.01.035.

[24] ASTM D5590-00, Standard Test Method for Determining the Resistance of Paint films and Related Coatings to Fungal Defacement by Accelerated Four-Week Agar Plate Assay.

[25] A. Popa, V. Sasca, E.E. Kiss, R. Marinkovic-Neducin, M.T. Bokorov, I. HolclajtnerAntunovic, Mater. Chem. Phys. 119 (2010) 465-470, http://dx.doi.org/10.1016/j. matchemphys.2009.09.026.

[26] R. Arreche, N. Bellotti, M. Blanco, P. Vázquez, J. Sol-Gel Sci. Technol. 75 (2015) 374-382, http://dx.doi.org/10.1007/s10971-015-3710-8.

[27] L. Salvatore, R. Romagnoli, B. del Amo, N. Bellotti, M.T. del Panno. Evaluación de la resistencia de pinturas frente a aislamientos fúngicos, Anales del $3^{\text {er. }}$ Enc. Jóv. Inv. Cien. Tec. Mat. SAM. N ${ }^{\circ} 11-12.2010$.

[28] C.S. Yang, P.A. Heinsohn, Sampling and Analysis of Indoor Microorganisms, John Wiley \& Sons, Hoboken, New Jersey, 2007.

[29] M. Moritz, M. Geszke-Moritz, Rev. Chem. Eng. J. 228 (2013) 596-613, http://dx. doi.org/10.1016/j.cej.2013.05.046.

[30] V.B. Bajpai, S. Shukla, S.C. Kang, Bioresour. Technol. 99 (2008) 8903-8908, http:// dx.doi.org/10.1016/j.biortech.2008.04.060.

[31] G. Teichmann, Concr. Precast. Plant Technol, 11 (1990) 58-73.

[32] L.R. Pizzio, P.G. Vázquez, C.V. Cáceres, M.N. Blanco, Appl. Catal. A: Gen. 256 (2003) 125-139, http://dx.doi.org/10.1016/S0926-860X(03)00394-6.

[33] P. Villabrille, P. Vázquez, M. Blanco, C. Cáceres, J. Colloid Interface Sci. 251 (2002) 151-159, http://dx.doi.org/10.1006/jcis.2002.8391. 